\title{
Usability Enhancement of SMS Interface for Illiterate Users
}

\author{
Farzana Kausar Gondal ${ }^{1}$, Syed Khuram Shahzad ${ }^{2}$, Muhammad Waseem Iqbal ${ }^{3}$, Muhammad Aqeel ${ }^{4}$, Hafiz Ali \\ Ahmed $^{5}$, Muhammad Raza Naqvi ${ }^{6}$, Tanveer Majeed ${ }^{7}$ \\ ${ }^{1,6}$ Department of Computer Science, Superior University, Lahore, Pakistan. \\ ${ }^{2}$ Department of Informatics \& Systems, University of Management and Technology, Lahore, Pakistan. \\ ${ }^{3,4,5}$ Department of Software Engineering, Superior University, Lahore, Pakistan. \\ ${ }^{7}$ Department of Biotechnology, Kinnaird College for Women, Lahore, Pakistan. \\ Email: Waseem.iqbal@superior.edu.pk \\ (Received: 09 July 2021 ; Accepted:02 Sep 2021 ; Issue Published: 12 Sep 2021)
}

\begin{abstract}
This article analyzes several User Interface (UI) designs and puts forward some more general design principles for interfaces designed for low-literate users. The results of this study highlight the importance of text-free interfaces compared to text-based interfaces for the illiterate and low-literate population. The study developed a Short Message Service (SMS) interface consisting of many design elements, including graphical icons, voice, and text reduction. The participants were more satisfied with the designed SMS interface as compared to the traditional text-based interface of SMS. We believe that if the user interface is appropriately designed, users will not need formal literacy, computer skills, or any external help to operate the application. It has been shown that an interface with minimal or no text but one or more graphics, audio, and digital components is helpful for users with low literacy rates.
\end{abstract}

KEYWORDS: Usability Enhancement, SMS, Interface, Illiterate, Low Literate

\section{INTRODUCTION}

\subsection{Android Application}

The android platform incorporates a range of crucial apps such as e-mails, maps, browsers, calendars, contacts, and several other resources. Applications are built in the Java (programming) language. You will fit into your next massive mobile application in this coating [1]. The smartphone is a device that is run by its autonomous operating system and incorporates unique functions on the touch interface. It is probable to always have third-party software installed and held everywhere in the operating system [2]. Mobile phones have only ever been optimized for calling and some are very prevalent due to various technologies, we can handle a lot of applications simultaneously. The advancement of smart devices is exceptionally fast. We can manufacture online messages, recalls, banking activities, Internet calls, telephone calls, e-mails, Etrade, games, and planning with some of these applications. The main consideration is responsiveness, short-term memory, and irrational fear to adjustment of technology. Potential challenges can entail text indicators in which error message is entered. Many low-literate users are not able to use smartphone devices because of their literacy levels, and they need a literate person for communicating with their family or doing some other task on the smart device. Respectively non-smartphones and smartphones there is a substantial usability discrepancy. In this context, we wanted to steal the distance between Smartphone use and [2].

Many people in the third world are unenlightened (incapable of reading, writing, and processing lowincome communities) (working hard to read, write and understand short messages). We relate to these two individuals with the expression low literate. Due to the extreme unprecedented advancement in mobile telephone performance abroad, this merely literate demographic has become the biggest growth business for mobile users. Along with their minimal grasp of reading, it is often hard to procure these facilities for lower poverty users. The obstacle of the low literary community using cell phones was tackled by rising product design [3].

\subsection{Literate and Illiterate Population}

Literacy is the ability to read and write in at least one method of writing, an understanding reflected by mainstream dictionaries, a person is said to be illiterate if $s($ he) can't understand reading and writing in a short, simple statement in everyday life [4]. So we make an efficient method for low well-educated.

\subsection{Literate and Illiterate Functionality}

This study formed a capacity in which multiple alternatives collect and transmit SMS through speech, images, reality, playfulness, and the use, who can't participate at all the other workouts in which integrity is crucial for the efficient functioning of both the network and network as well as for the maturity models of reading, drafting and processing for the 
productivity enhancement. A person who can participate in each one of those exercises in which proficiency is needed for the compelling working of gathering and network and for empowering to keep on utilizing reading, composing, and computation for his own and the network's development [4].

\subsection{Low Literate Population}

The order of communicating, comprehends, interprets, develops, and registered via published and assembled adjustments material. Business acumen involves knowing endlessly enough so citizens can accomplish their goals, learn stuff and scenarios and actively engage in structures and Core concepts in education are cooking classes' squares, but instructions such as the recognition of normal chores such as intercity buses, product descriptions, news stories or medical training are difficulties for a vast proportion of adults. Around 25 percent of workers (ages 16 to 65 ) were rendered theoretically illiterate in 2000 in rich countries throughout the world [5].

Table 1. Comparison between Text versus Voice \& Graphics and Live operator

\begin{tabular}{|l|l|l|}
\hline Components & $\begin{array}{l}\text { Study 1: Text versus Voice and } \\
\text { Graphics }\end{array}$ & Study 2: Text versus Live Operator \\
\hline Task & Proper transfer on compact trading & Enter details on welfare with tiny faults \\
\hline Interfaces Compared & $\begin{array}{l}\text { Expression communicate Virtual UI } \\
\text { Text (USSD) }\end{array}$ & $\begin{array}{l}\text { Text (Electronic Forms) Thrive Supervisor } \\
\text { Text (SMS) }\end{array}$ \\
\hline Subjects & $\begin{array}{l}58 \text { topics that aren't even educated and } \\
\text { mid (Bangalore, India) }\end{array}$ & $\begin{array}{l}13 \text { fluent government professionals and } \\
\text { medical professionals (Gujarat, India) }\end{array}$ \\
\hline $\begin{array}{c}\text { Preparing and Testing } \\
\text { No }\end{array}$ & $\begin{array}{l}\text { Provokes available mostly during } \\
\text { analysis }\end{array}$ & $\begin{array}{l}\text { No equipped with a special mostly during } \\
\text { tests practice before they became worthy; }\end{array}$ \\
\hline Results & $\begin{array}{l}\text { Unserviceable text framework without } \\
\text { preparation Required to speak } \\
\text { exchange: only 72 percent of } \\
\text { respondents accomplished but } \\
\text { efficiently with much less support } \\
\text { Figure UI: 100\% of matters done, but } \\
\text { rapidly and concisely }\end{array}$ & $\begin{array}{l}\text { High blunder rate on content interfaces: 4.2\% } \\
\text { for Forms, 4.5\% for SMS Live administrator } \\
\text { (0.45\% mistake rate) }\end{array}$ \\
\hline Recommendations a significant degree \\
$\begin{array}{l}\text { Semi require non-text software } \\
\text { platforms Speak details may intensify } \\
\text { the advantageous of attentive } \\
\text { implementations procedural gain }\end{array}$ & $\begin{array}{l}\text { Where it is efficient to do as such, utilizing a } \\
\text { live administrator is desirable over content } \\
\text { UIs for versatile information assortment }\end{array}$ \\
\hline \multicolumn{2}{|c|}{}
\end{tabular}

Table 1 shows the difference between Text versus Voice and Graphics \& Live operators. The results show that the blunder rates were high in live operator as compare to voice and graphics. For Low-Resource Users, Voice-based Systems, including IVR systems, for services such as agriculture knowledge, petition mended and social media have been developed to accommodate limited resource users [6]. Persona systems, such as IVR, are designed and manufactured for wealthy users with limited infrastructure and for applications, such as the Resolution of Agricultural Awareness Inquiries Media Conglomerate for the District [7]. The awareness of data has impacted many people and has been a vital communication method [8]. This phase of details has changed dramatically the way people think and communicate. Because the human brain is attracted to sight, the concept of information is used to visualize information through vision. For this reason, a variety of scenarios have been developed over the years.
The use of the technologies for expressions, smartphones in simple text, which can still be read promptly, reiterated, and sometimes at your discretion, enhances information center by typing. But for the illiterate population, we send SMS through image, voice, movement in the video, in any color and symbol.

\subsection{Short Message Service}

Texting is communication by writing made possible by technology for the spoken word, the mobile phone in the simple text that can be read immediately, repeatedly, or even at leisure. Moreover, messages can be sent quietly and hence privately between communicators who may even be engaged in other activities such as traveling on public transport, watching television, attending meetings, classes, or lectures [9]. But for low literate users, we send SMS through image, voice, movement in the video, in any color and symbol, etc.

\section{LITERATURE REVIEW}


Everyone spends a lot of time on their smartphones and never even looks up. Just send me an email and we will make a schedule. All documents can be listed on our website, you can sign up online here anyway[10]. As of 2015, there are approximately 685 million mobile phone subscribers on the African continent, equivalent to about three mobile phones for every four residents [4]. However, Adults with low literacy levels never make sense of some of these innovations and cannot use telecommunications technology and techniques that most believe to be natural without reading ability [10]. Currently, 800 million illiterate people do not have the benefits of asynchronous and cheap communication through SMS [11]. New universal computerized gadgets and sensors in underdeveloped countries are developing, like texting, Facebook, Twitter, savvy phones with sensors, the Network, and worldwide areas. Fathom that the procedure of the utilization of these developments is just literates. The United Nations (UN) recognizes a keen society somebody who can obviously see, peruse and compose sums [12]. Numerous regular people in developing countries are unskilled. Basic messages and messages can't be perused, composed, and acknowledged; and semiproficient instant messages can't actually be perused, decipher, and decipher. The word low proficient commonly alludes to these two people.

On the other hand, it is now and again hard for the buyer with restricted English capability to flourish from such an exchange because of the lacking proficiency abilities [13]. The documentation isn't current. The investigation showed that an everincreasing number of analphabets using Personal Digital Assistants (PDAs) ought to be utilized for powerful programming, affecting them to react to demands contingent upon flip switches, the green telephone reaction button, and the red telephone denying calls. Numerous proficient issues, like SMS, were seen never to utilize text-based capacities. This was likewise scrutinized that most of the members may use the touchscreen, yet not many scholars might have utilized Hindi even because they communicated in Hindi [14]. Internationally, 800 million understudies can talk or have a go at writing in their local tongue. Most dwellings in developed countries rest in rustic regions [12].

To a great extent, the utilization of the SMS counsels extends from specialists to Inland Revenue. It reflects how SMS channels' development force draws on coordinated exercises in the organization [15]. The effect of text informing is genuinely low with regards to future impedance. It tends to be enhanced, sent distantly, is helpful for medium-advanced proficiency, and arranged instructor's dissemination. Wellbeing associations can give and control these advanced apparatuses while new and creative applications that can take out the restricted availability and life span of instant messages are identified [16]. Specialists examined the utilization of such content-free representation apparatuses and voice applications to address language and perception issues [17]. There's an intentional rule over the utilization of less easy to use text and a touch screen plan for the rich visual experience, explicitly by the utilization of shading coded graphical UIs and voice marking in local tongues [14]. Slated versatile messages and messages have improved incredibly similarity with ART [3].

In areas with a lot of semi-clients and perception agendas of essential extent, that is particularly inconvenient. In this venture, we accentuate the verbally expressed exercises created in underdeveloped countries for near-zero clients. The ease of use is considerably higher than even a catch structure with a very much designed voice interface [18]. The introduction of the Commission on Biodiversity People needs improved activities abilities and the capacity to peruse and pick, depict and clarify research results. The analphabet in this way is not pretty much as incredible as the view of the proficient [19] shows that mindfulness is a gigantic presentation great indicator [18]. The introduction of the Conference on Fisheries Analphabetism is getting one of its reality's greatest obstacles. Some other significant concern that has reinforced the age hole is Personal Computer (PC) conceivable security. The idea of the UI should deal with analphabets, semilearned, and proficient internally [19].

In Canada, half of the youthful grown-ups are seen as having helpless social abilities in literacy [5]. With western instruction empower of per user, those grownups with a low degree of proficiency are developing. The Information and Communication Systems (ICTs) of a day are increasingly more essential social and symbolic. In 2008 there would be more than 4 billion web clients, just as about $60 \%$ of memberships are in developing economies [20]. A few of the disadvantages of getting to such framework, even though, will be that in monetarily progressed countries, $41 \%$ of the all-out populace is gravely instructed [UNESCO 2007] however even the poor are at last nearby clients of computerized innovation. Going before survey reveals that near-zero educated social orders disregard assorted calculations and prevalently use innovation to convey simultaneously [24].

The study had a very well discourse Touch-tone: Speech about touch: Telecom Devices for Low Literate Users' direction of the pivot permits both lowlevel processing and proficient clients a touch-tone equal that majorly affects task accomplishment with the two interfaces. Ideally, soon we depict and put the 
implications of these impacts from a more extensive perspective. Gadget costs are reducing rapidly, and inhabitants across financial classes are relevant to an assortment of items, from telephones and PC to versatile tablets [20]. At the point when we respect cell phones, about 6.9 trillion of them live in cutting-edge nations of the world and 78 percent of administrators. A telecentre is a typical site where people share admittance to PCs and surprisingly the Net. They then fortify their range of abilities, can build up to them, and learn and talk with others using various knowledge base systems or expert systems using services integration [21]. Broadcaster's optional occupation is to help fabricate a group of people by broadening well-being, encouraging medical conditions, advancing exchange benefits, and pulling in youthful people. In 41 countries, $85 \%$ of the noneducated inhabitants live in the middle of the least advanced and the least developed [20]. Discoveries show that non-educated societies oppose assorted calculations and use telephones exclusively for coordinated vocal-only [9]. Indeed, even the contact component on their devices is too difficult to even think about utilizing this for some modest individuals, so they dial hundreds any time a voice call is fundamental [1].

In fact, there truly is motivation to envision that the UI model for low-proficient clients ought to likewise be remarkable despite having an alternate wide scope of psychological abilities. We much of the time raise points when carrying out tests in low-pay, low-level populaces and specialists in innovation. Throughout the previous few years of UI research where it has introduced non-printed plans, we assess perhaps a few models. We study research acted in non-proficient people. This account does exclude relationships with individuals. Different parts of explored making content are pen and contact data [17]. Video preparing was utilized to vanquish the unsuitableness to peruse the content to bring down skillful users [25].

In corresponding to the entirety of the above mentioned, longitudinal examinations have endeavored to look at the adjustments in a different mix of cycle technique for treatment from unyielding too inflexible in 5 contributions (first off, input typeout, coordinated discourse, and opportunity of assessment). For low-level clients, we help form model direction given the current advancement. The SMS use ought to be risen significantly [20]. In 2016, there are 133,24 million broadband customers, and more than 301,7 billion phone messages were shipped off 2014 [21] by the Pakistan Telecommunications Authority (PTA). Limited parchment bar, utilization of such numbers, madly route, limited interfaces, and doled-out catches would be remembered for different components in its design [1].
We even glance at development for client - welldisposed interface however, for experienced and educated clients who do utilize signals, language, feel, and different properties of regular commitment (Windows Phone 2014, Google, 2014, recovered July 18, 2014). Through different models, we address how practical models ought to cross with capable services Technology reads for a miniature - big names raise travel distance and family jumps. In current history, its utilization of cell phones has diminished to 44 percent in 2017 in sub-Saharan Africa. It is anticipated that this measurement will approach billions of dollars by 2020, which will give the African cell phone market the most grounded developing [16]. Live in a world, 800 million unskilled workers don't harvest from synchronous and advantageous SMS connectivity [15]. However, the emission in PDA use sending altogether progressed nations [22] exhibited the solid spotlight on tech. Many examination works have been conveyed together to give a groundbreaking ICTbased foundation to the populace in provincial regions of the developing scene [23].

\section{IMPLICATION OF SMS SYSTEM}

We concentrated on the messaging apps in this text. The bigger implications are documented in the interviews. Because our Swiss learners stayed in a foreign place, they will now have to keep in contact with family and friends and friends at home. Catching abroad was troublesome and they mostly made calls to Internet cafes through military personnel or VoIP's which wanted to be arranged at one moment with the band. Many see intermittent communications like SMS as a convenient and cost-effective means to interact. Because each interlocutor said, if others would not even have a call, I would like to deliver an SMS, but it is too challenging.

In conjunction, others had been expected to bring text so rather than calling. His dependency on reading appeared an impossible task to his use for citizens. SMS has also been sent to both of them. The processing of text messages earned differed and depending to some extent on certain quality. Most panel members have been processed to seek connections via SMS bearing cell phone numbers for months. Most individuals who consulted replied to the received SMS by calling the sender, either by downloading the contextual menu or by putting it back on the screen. All of the other people who were surveyed handled all of the text as either spam and discovered how to quit or immediately uninstall themselves without verifying everyone's content or sources - those around sought guidance with the text messages substance. One person asked whether that would be possible to send the SMS to both a provider and listen to something like the information with a 
voice signal or a computer response on the phone. Any members had difficulty reading documents for the invoice. They never signed paperwork without the presence of a reliable option to perform sure documents were not violated.

\subsection{Voice-Assisted SMS Application}

Oriented by the findings on use of the non-use of SMS by uneducated folks and their interest in such communications, the system for something like a personality SMS implementation was recommended. The premise was also investigated in paper and that these early assessments became predicated on the premise of sending an SMS via icons only. Audio assistance for icons was beneficial, particularly after you first watch it, to prevent mischaracterizations. Besides this, any errors will safely be restored by erroneous editor phrases. The catalog of icons was reduced, but we believe it will be a place for illiterate users to build things to express themselves. A voice activation facility will naturally be more scalable and deeper.

\subsection{Icons Assisted SMS Application}

This study begins with the three individual variations of several other icons, which were both displayed along with the same screen from clear guidance. Over the first experiment, we correlated the well before the version with either the bubblegum version or the second prototype. Note that visitors must tape the icon to listen to the entire power requirement in a row in the also before the version. Users were asked to tap and hold the icon in the popup version and the accompanying keywords provided a little squeeze on the computer. Participants will now have to quickly tap it to assign a word. We advised them to press the low- and mid-button from every edition and asked if they would have an idea how to add several of the subsequent regional to the communication editor. We, therefore, include them in the main agreement for the composition: Suppose you received a text message from another friend. Users would have seen that your INBOX contains a blog position. Tap through the post now to find out is why you give this SMS to you again when we navigate the Chats tab, we let them react, and press the record button there with an SMS post, to what your contact posted.

It means you sound pleasant to use the SMS software using someone's personality with the icons. Those who will now have to evaluate the composed document by hitting on the share button before transmitting it. Our first citation for information gathering was also the videotapes for information retrieval. We investigated the documents and evaluated the kind of errors they had made and on which screen on each job they were already done.
Nevertheless, we cannot perform numerical analyses due to the small group of participants. We wondered whether the interface was straightforward to use during the opening interviews and if icons were supportive in their everyday routines.

\subsection{Graphics/Images Assisted SMS Application}

Many SMS apps aren't really acoustic, can be used by the user to learn documents and audio. We don't really want to say the mobile wallets receive an education there with this query. But we see scope for it in virtual communities with text that includes functional comprehension known as restriction sites objectives and thus stimulate and incentivize the attainment of literacy. Chiefly the fact that after the withdrawal of the karaoke showcase, our stakeholders haven't really been useful to intercept words convinces us how this functionality is favorable to illiterate, neo-literate, and authoritative users every day. The text consumption can also be seen to strengthen reading and writing SMS in researchers in paired with audio and video in much the same language.

The sounds played while touching keywords and icons could hardly show consider the value of a user to something like the residents using our programmed. In addition, our program sends all SMSs regularly. If a texting sender tells an SMS, the receiver cannot know that a written submission for analphabets. Research findings of alphabets have always shown that it is indeed a struggle as they're not abundant and as they mostly strive to disguise consider the value. To overcome these kinds of challenges, we suggested an SMS application consisting of graphics so that a novice/illiterate user could benefit from it by using it.

\subsection{Display Content Clearly}

Content display precisely introduces clinical distinction in a straightforward, consistent way that will make knowledge interesting to understand and available. Grouping information is a short period of parts or comparable classes of object processes and information. Cognitive learning eliminates information in one area and helps consumers to retain the information more effectively. Cutting avoids information overload and would be the perfect way to view the documentation on mobile device devices. When trying to design software, the narrower screen size of portable devices plays a huge role. Metadata must be graded and filed [26].

\subsection{Organize and Simplify}

To arrange and simplify directions to use the result in continuous and nice design to significantly boost the comprehension and facility of application areas, especially for the low productivity demographic. Cohesive management improves the user's volume of 
work and impedes the switchover both to and from

media channels.

Table 2. Same context usability enhancement applications for illiterate users

\begin{tabular}{|c|c|c|c|c|}
\hline SR\# & $\begin{array}{l}\text { Reference } \\
\text { \&authors }\end{array}$ & Subject Studied & $\begin{array}{l}\text { Technology } \\
\text { Discussed }\end{array}$ & Description \\
\hline 1 & {$[1]$} & $\begin{array}{l}\text { Low Training Group } \\
\text { Health Workers mobile } \\
\text { workstation endorse }\end{array}$ & $\begin{array}{l}\text { user interface } \\
\text { development }\end{array}$ & $\begin{array}{l}\text { This research has been done in the northern } \\
\text { province of Chhattisgarh, Bester District, } \\
\text { India. } 97 \text { decreased and intermediate } \\
\text { participants were highlighted in this section } \\
\text { of interpreting wireless usability, whereas } 18 \\
\text { first interaction subjects and } 24 \text { second } \\
\text { activity respondents were recruited within } \\
\text { the same domain of UI Interface research. }\end{array}$ \\
\hline 2 & {$[2]$} & $\begin{array}{l}\text { Efficacy of short dialog } \\
\text { and voicemail } \\
\text { transcription strategies }\end{array}$ & $\begin{array}{l}\text { Antiretroviral } \\
\text { therapy adherence } \\
\text { (ART) }\end{array}$ & $\begin{array}{l}\text { A wider spectrum of chapters covered non- } \\
\text { RCTs and cell network voice calls. The } \\
\text { current findings of the study would fill a } \\
\text { fundamental void in comparison to primary } \\
\text { specifically focused on Communications and } \\
\text { SMS measures. }\end{array}$ \\
\hline 3 & [7] & $\begin{array}{l}\text { WhatsApp can be used } \\
\text { by Rwandan journalists } \\
\text { to boost their } \\
\text { occupation }\end{array}$ & $\begin{array}{l}\text { Social application } \\
\text { WHATSAPP }\end{array}$ & $\begin{array}{l}\text { This research assesses how journalism is } \\
\text { intertwined in social media and probably } \\
\text { contributes to improving immersive } \\
\text { journalism paradigm technology. }\end{array}$ \\
\hline 4 & {$[8]$} & $\begin{array}{l}\text { The groundbreaking } \\
\text { platform is driven by } \\
\text { increased technology }\end{array}$ & $\begin{array}{l}\text { SMS Application } \\
\text { to Person }\end{array}$ & $\begin{array}{l}\text { Wanted to explore Norway's SMS A2P early } \\
\text { development. Enthusiasm is vital for the } \\
\text { development of subscription services in the } \\
\text { system. Second, mobile network } \\
\text { intermediaries and distributors were } \\
\text { remarkably successful at striking the right } \\
\text { balance between responsibilities in relation. }\end{array}$ \\
\hline 5 & [11] & $\begin{array}{l}\text { Message text } \\
\text { information }\end{array}$ & $\begin{array}{l}\text { Designing a } \\
\text { mobile phone } \\
\text { application(SMS) } \\
\text { for illiterate users }\end{array}$ & $\begin{array}{l}\text { Include an estimation of the accessibility of } \\
\text { both severely handicapped applicants for this } \\
\text { allow maximum from the assessments and } \\
\text { the success of its concept. }\end{array}$ \\
\hline 6 & {$[13]$} & $\begin{array}{l}\text { Use or the architecture } \\
\text { ecosystems: urban } \\
\text { Bangladesh's Rickshaw } \\
\text { puller societies }\end{array}$ & $\begin{array}{l}\text { Mobile Phone } \\
\text { Use Within Low } \\
\text { Literate }\end{array}$ & $\begin{array}{l}\text { We start debating the literacy roadblocks that } \\
\text { our research instrument discovers to use and } \\
\text { the content providers and links that } \\
\text { individuals use to work around these } \\
\text { barriers. We conclude with prototypes and } \\
\text { more broad research proposals that could } \\
\text { strengthen the researchers' suite of tools to } \\
\text { properly approach this and several other } \\
\text { problems. }\end{array}$ \\
\hline 7 & {$[14]$} & $\begin{array}{l}\text { Mobile phone users } \\
\text { with illiterate and poor } \\
\text { literacy: do they get } \\
\text { literacy? }\end{array}$ & $\begin{array}{l}\text { Mobile phone } \\
\text { usage }\end{array}$ & $\begin{array}{l}\text { The availability of alternative functional } \\
\text { mobile telephones at specialized reading } \\
\text { skills to rural language learning on } \\
\text { something like a gradient of linguistic skills. }\end{array}$ \\
\hline 8 & [17] & $\begin{array}{l}\text { Low-Literate and } \\
\text { Novice Users }\end{array}$ & $\begin{array}{l}\text { Video } \\
\text { Content(VideoKh } \\
\text { eti) }\end{array}$ & $\begin{array}{l}\text { We characterize Video Kheti design and } \\
\text { implementation and record a literature } \\
\text { review with } 20 \text { various Parts of India farmers } \\
\text { who have just been tasked with finding } \\
\text { scenario video clips. }\end{array}$ \\
\hline 9 & [20] & $\begin{array}{l}\text { Limited users' health } \\
\text { information }\end{array}$ & $\begin{array}{l}\text { Speech-based } \\
\text { Access }\end{array}$ & $\begin{array}{l}\text { Monitor and interpret the background of a } \\
\text { pilot study relating to healthcare workers' }\end{array}$ \\
\hline
\end{tabular}




\begin{tabular}{|l|l|l|l|l|}
\hline & & & $\begin{array}{l}\text { application in a rural community clinic in our } \\
\text { recommendation regarding exposure to } \\
\text { health programs. }\end{array}$ \\
\hline 10 & {$[28]$} & $\begin{array}{l}\text { Feasibility Analysis of } \\
\text { User Interfaces for } \\
\text { Illiterate Users }\end{array}$ & $\begin{array}{l}\text { Systematically reviews the work carried out } \\
\text { by HCI4D researchers in four different } \\
\text { domains i.e., health, agriculture, e- } \\
\text { commerce, and education. We have } \\
\text { extracted User Interface (UI) design } \\
\text { recommendations from the related literature } \\
\text { for UI designers of these domains. }\end{array}$ \\
\hline
\end{tabular}

\section{METHODOLOGY}

The SMS) is a simple mechanism for the mobile phone industry to help us understand the fundamental obstacles of implementing interfaces mobile applications for the growth vigorously or subassemblies. We first study their adaptability to mobile phones. Our focus is to understand the level of illiteracy of people, which includes what features they use and how they interact with mobile phones.

In addition, this study also focused on how they use touch screens; especially our focus is to understand how illiterate people use SMS services on their phones. Interviews were conducted as quantifiable research. The theme will be selected according to our requirements. The level of education in our subjects has never been to school at all, and there is a range of elementary education. Geographically speaking, all topics will come from different regions. The main languages of the subject are Urdu and Punjabi. Nonprinted UIs were planned, dependent on the plan standards we had set up, utilizing mixes of voice, illustrations, and video to help conquer ease of use hindrances [24]. Through ethnographic and ease of use contemplates led during this UI configuration research, we found a large group of nuanced issues, past severe ease of use, which could additionally illuminate the plan regarding UIs for these populaces. Most aspects can be divided into two main groups, based on empirical evidence of the use of digital devices, including people who have seen it but don't own it, and groups of people who already have it. The interviews will be based on a structured format, with each subject lasting approximately 15 to 20 minutes. This data gathering emphasizes making the use of cell differentiation telephone features. The major responsibilities required: reading, composing, sending, and understanding SMS.The interview will be divided into five main parts: introduction, biography of participants, motivation to use the mobile phone, use of SMS application, and the efficiency of SMS applications.

The topics of the conversation were constructed to demonstrate the use of mobile technology, especially the use of SMS applications. The questions in the interview will enable attendees to contribute their own views and experiences into the incident about How do we increase the usability enhancement of the SMS interface? In the interview, different questions will be asked, which includes:

- Have you used a mobile phone and how?

- How do you connect with others?

- Are you having difficulty using the SMS application?

Do you think that your mobile SMS application is effective enough for you to send and receive SMS [7]. Most illiterate people use calls instead of text messages because they cannot send and receive text messages. People can use SMS text-free or contain less text because people cannot even read or write in their native language. Using these methods can help enhance the usability of the SMS such as: avoiding text, using graphics semi-structured, increase attention to graphic prompts, provide voice feedback for all function icons, and provide help on the screen [25].

In the end, we will propose different design suggestions to improve the usability of SMS applications, such as:

- Avoid text-based input even when using local languages

- Graphical interface with integrated color coding

- Provide voice-based annotations

- Integrate audiovisual effects

- Avoid using a complicated menu.

\subsection{Participants}

This study undertook moderately question list interactions. For all of those who live in Pakistan. The vast majority of them reportedly have no particular infrastructure work. The interview included a summary of a regular day, complications or shortcomings, the gadgets used at home, the uses of communication devices, with strong attention on digital mobile use and calls, notably SMS applications. The interview consisted of different parts which includes: a social and economic assessment, a 
discussion single or multi, instant messaging interface functionality review, and tool Diameter of numerous SMS software

This study addressed and aim to establish a mutual understanding with the informants before the beginning of this study, The participants were convinced that they couldn't read or write common commands. Between messages writing. And as such, no further comprehension exams have been worked out. Since we desired to foster an ecosystem that empowered the adolescents to provide input in a forthright manner, we deemed literacy assessments detrimental to this intention. The questioning focused entirely on their daily use of cell phones and SMS. Everybody was challenged to show their cell telephones and their vital roles. In particular, empirical evidence was provided in which metadata was monitored, saved contacts, and coordinated with SMS on your phones. We took great care by the interrogator on-site and a recording device that monitored the activities and the exchanges with the respondent on their cell phone.

By displaying the query, a feasibility study was conducted. We browse through assorted devices, come up with new messages, hear a new message, and address a message by doubling icons and emphasizing previous symbols' current expressions. They were asked what their perception would be before referring to the meaning of collected icons. They were requested to diagram or articulate whether they could realistically illustrate a thought if they can still not decipher the essence of an image we used on the mediated activation. We, therefore, explained how to trigger a document's audio analog by clicking on it. The participants were instructed to recreate the corrupt practice during that same event and we urged them to scan, press, and touch the same screen to experience the touchscreen user experience.

Mostly during the session, we managed to provide all descriptions have used simple, non-technical terminology. For example, we called numbers, letters, and icons "mini images." the students, for starters, had no knowledge about aspects such as applications and icons. They were enabled to communicate about every issue or component that they can't understand. It would not be their fault, but still, the engineers because they people do not understand the product or part whatsoever. A thorough review was commenced, reflecting on low- and mid-icons, the arrangement, and listening of the message (and especially the karaoke functionality), when one felt more confident and appreciated the system's key features.

\subsection{Experiment and Results}

Interviews were conducted regarding cell phones and text messages in Pakistan, targetting to know how to cope with illiterate people's defense mechanism, how and when to use mobile devices, and certain tactics to conquer their reluctance to read and write SMS. The students figured it impossible to believe what would occur from this survey if dignity, transparency, and eventual reward were a guarantee to them all in trade.

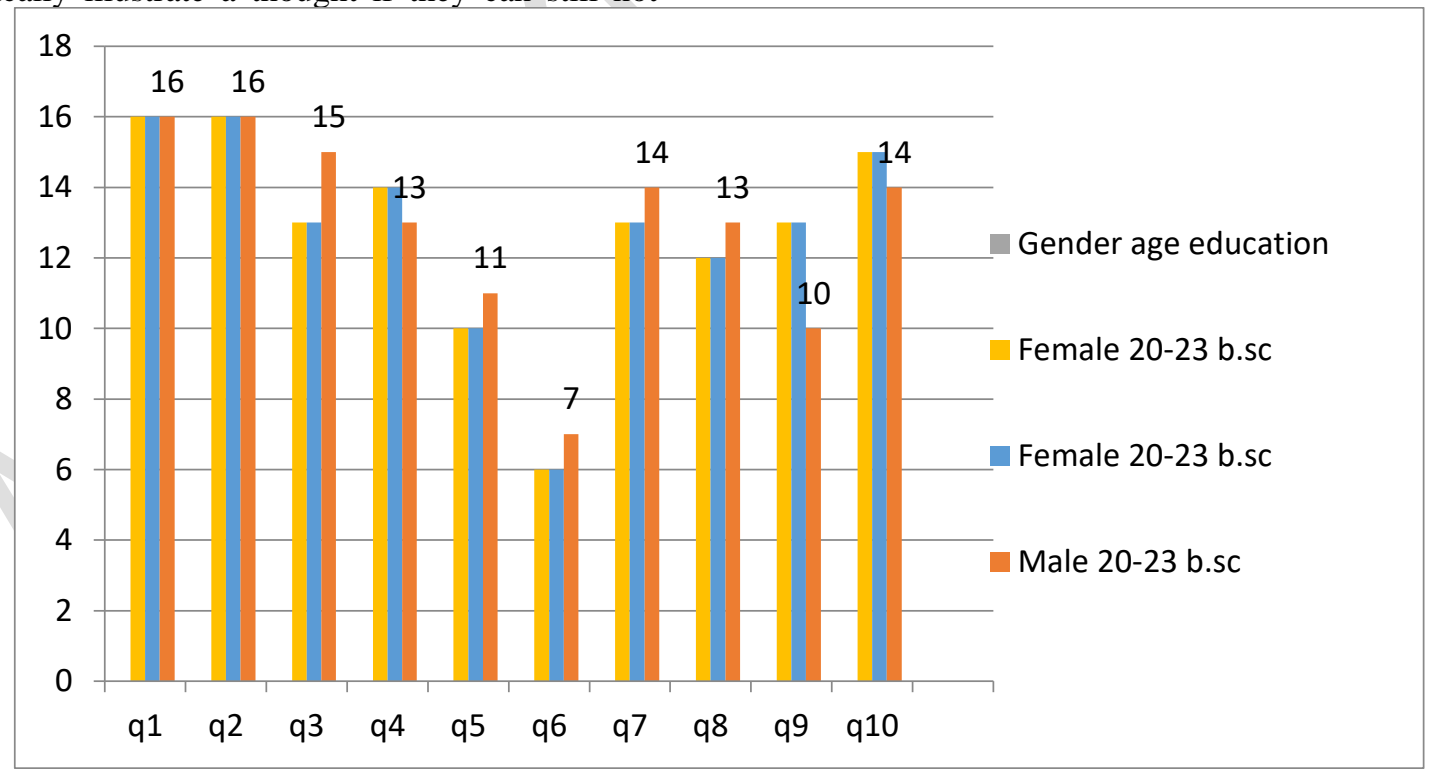

Figure 1: Participants of age between 20-23 years and with the education of BSC. Questions 1 \& 2 result in the highest score which is 16 and question 6 results in the lowest score which is 7 


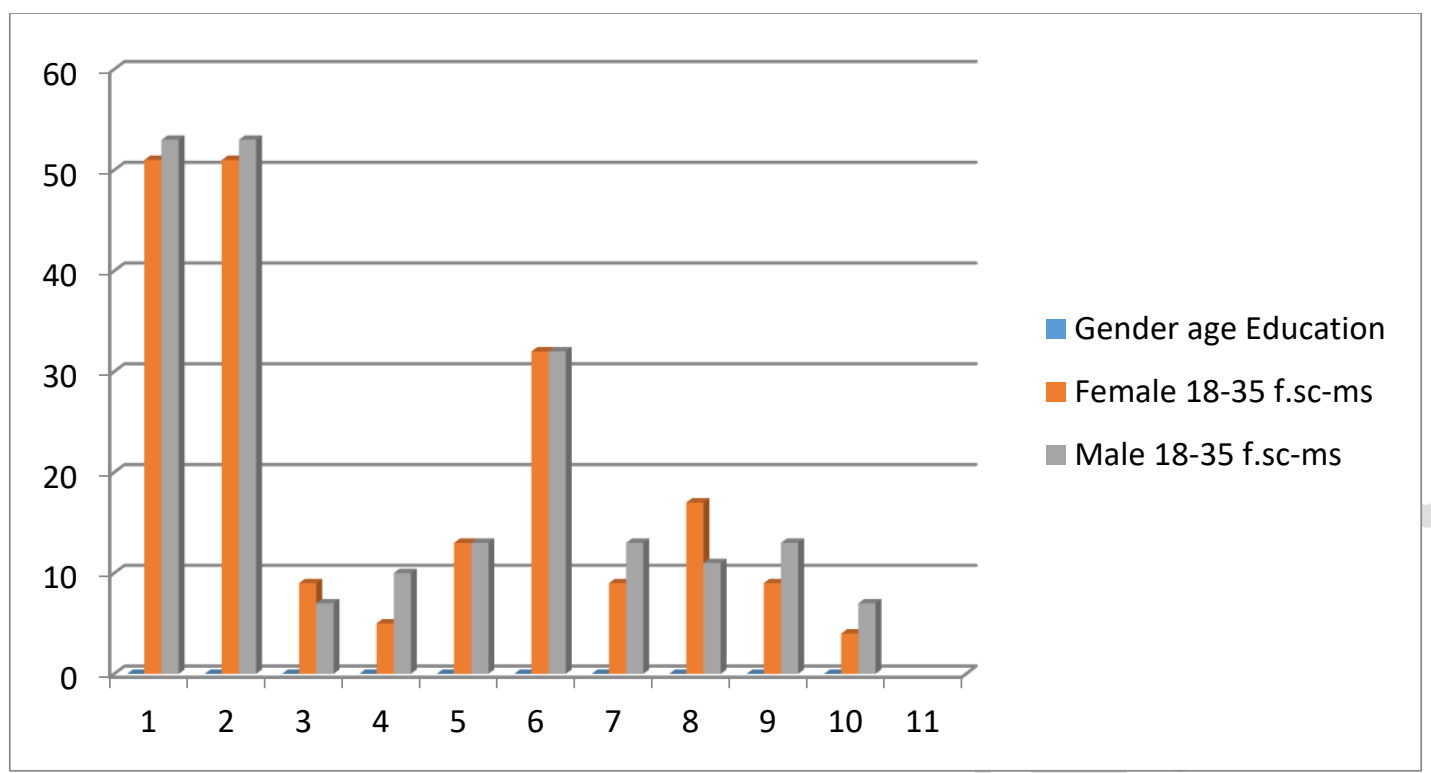

Figure 2: Participants of age between 18-35 years and with the education from FSC to MS. Questions $1 \& 2$ result in the highest score and question 10 results in the lowest score.

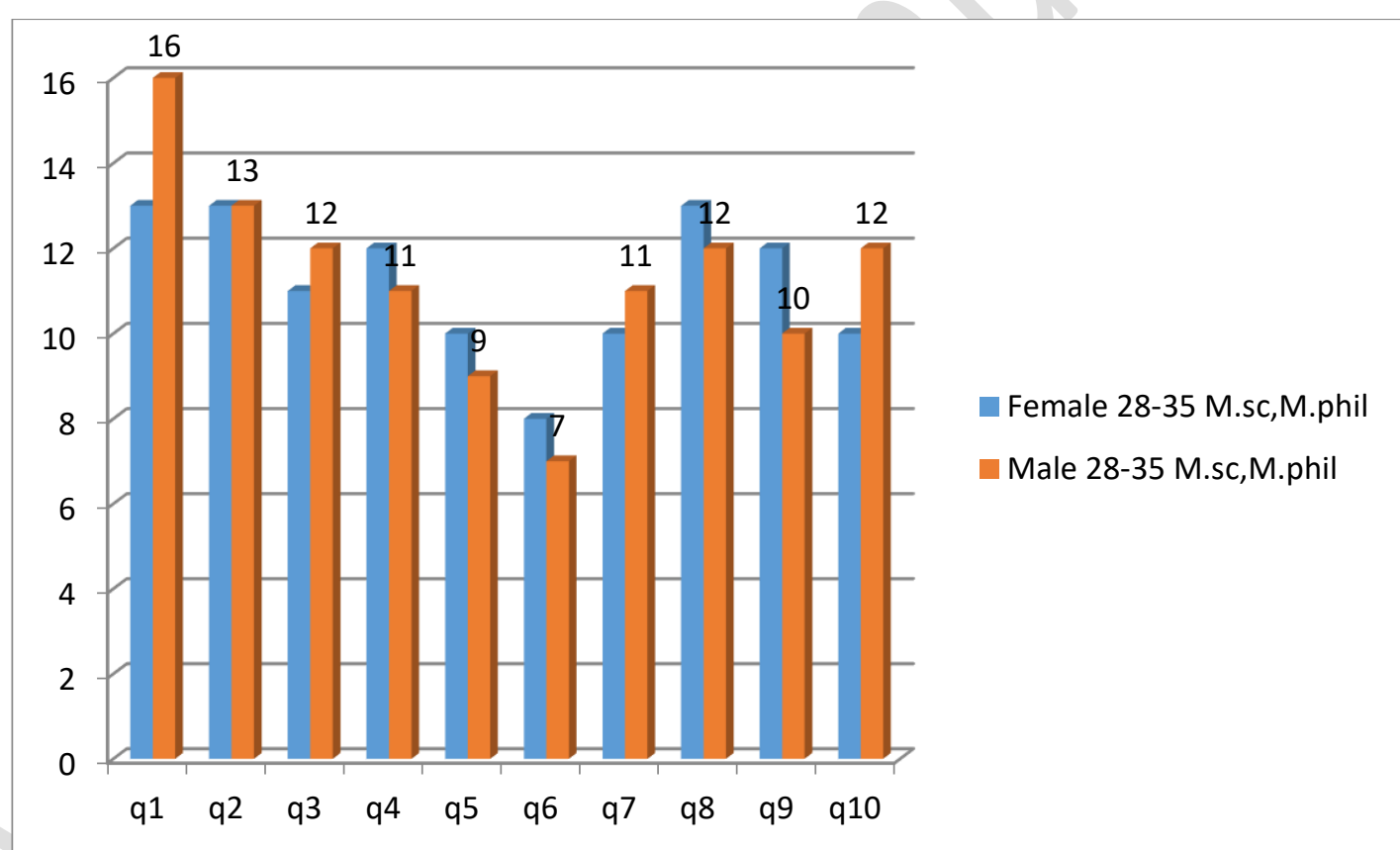

Figure 3: Participants who contacted each other through call. Total users were 104 including 50 females and 54 males. The age of participants ranges between 28-35 years and with the education MSC, Mphil. Questions 1 results in the highest score and question 6 results in the lowest score. 


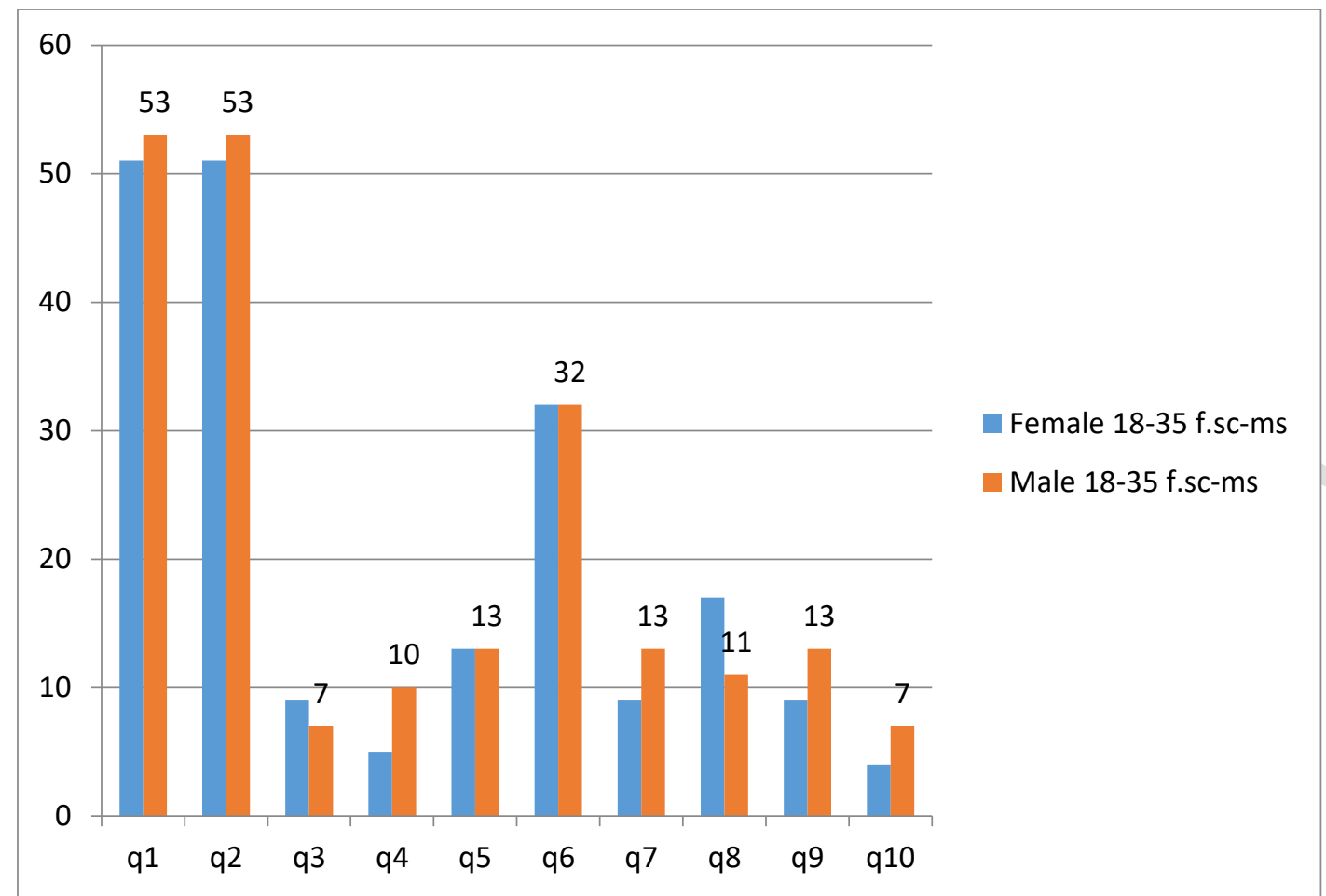

Figure 4: Participants of age between 18-35 years and with the education from FSC to MS. Questions 1 \& 2 result in the highest score and questions 3 \& 10 results in the lowest score.

\section{CONCLUSION}

Devices such as mobile phones have been very important these days and these devices should not target literate users only. It is a great priority to provide technology for users and populations with low literacy rates. In the previous, the concern of successful UI design in low read/write conditions is already discussed in this sector in some direction. One of the greatest hurdles would be that significant variables are hampered in existing literacy skills while creating applications for expanding societies. This study explored different modalities including voice and graphics for low-literate users in comparison of traditional text-based interfaces. The current material on development tools for analphabets emphasizes analphabetism as an issue that is not accessible. Previous investigations into analphabetism in developing nations illustrate that analphabet users have varying capabilities to use SMS services.

A full potential to use SMS does seem to be an integral ingredient for cell phone users. In this review, we explored whether unregulated users should use SMS or decline to use SMS. That was resulted just by analyzing student and non-editors from the Pakistani culture by analyzing the case interviews with illiterate users and mapping semi-literate users. An interpretation checklist was generated for illiterate participants and a dataset for other literate and semiliterate users in order to recognize participants. The results revealed that both groups have created different results, with literate learners mostly using SMD applications as opposed to non-cultural participants due to a lack of interface design. This is because SMS programmers are to be used. Now there are complications. The analysis concentrates on how SMS frameworks for analphabets are crafted. This is founded on the outcomes of literary reviews and surveys with the illiterates.

This study concludes that, illiterate users should use a text-free interface for sending and receiving SMS. In the development of SMS applications for illiterate users, we considered many design elements, including graphic icons, voice input for particular functional units, reduced text usage, and mode of production reaction to any input and instead icon graphics and compatibility of SMS applications. The findings also suggest that our researchers favored free design compared with a traditional text-based interface. This study concluded that there should be different interfaces for a low-literate and literate population. Low-literate users can also benefit from different applications and be more productive.

\section{REFERENCES}

[1] J. Feichtner, L. Neugebauer, and D. Ziegler, "Mind the Gap: Finding What Updates Have (Really) Changed in Android Applications," Proceedings of the 16th International Joint 
Conference on e-Business and

Telecommunications, 2019.

[2] Rajibul Anam and Abdelouahab Abid, "Usability Study of Smart Phone Messaging for Elderly and Low-literate Users" International Journal of Advanced Computer Science and Applications (IJACSA), vol 11 , issue 3, 2020.

[3] I. Amankwaa, D. Boateng, D. Y. Quansah, C. P. Akuoko, and C. Evans, "Effectiveness of short message services and voice call interventions for antiretroviral therapy adherence and other outcomes,": A systematic review and metaanalysis PLoS One, vol. 13, no. 9, p. e0204091, 2018.

[4] J. I. Campbell et al., "The Technology Acceptance Model for Resource-Limited Settings (TAM-RLS): A novel framework for mobile health interventions targeted to low-literacy endusers in resource-limited settings," AIDS and Behavior, vol. 21, no. 11, pp. 3129-3140, 2017.

[5] C. Munteanuet al., "ALEX: mobile language assistant for low-literacy adults,”, pp. 427-430, 2010.

[6] M. A. Madaioet al., "“ You give a little of yourself” family support for children's use of an IVR literacy system,", pp. 86-98,2019.

[7] H. Baytiyeh, "The uses of mobile technologies in the aftermath of terrorist attacks among low socioeconomic populations," International journal of disaster risk reduction, vol. 28, pp. 739-747, 2018.

[8] B. N. York and S. Loeb, "One step at a time: The effects of an early literacy text messaging program for parents of preschoolers," National Bureau of Economic Research, pp. 2898-2937, 2014.

[9] Naqvi, Muhammad Raza, et al. "Study of Block Chain and its Impact on Internet of Health Things (IoHT): Challenges and Opportunities," 2020 International Congress on Human-Computer Interaction, Optimization and Robotic Applications (HORA), IEEE, 2020.

[10] F. D. H. Cobb, “ IWanna Text, Too!” Examining How Low-literate Adults Use New Communication Technologies and Applications". North Carolina State University, 2013.

[11] E. Friscira, H. Knoche, and J. Huang, "Getting in touch with text: Designing a mobile phone application for illiterate users to harness SMS, ,' pp. 1-10, 2012.

[12] H. Knoche and J. Huang, "Text is not the enemyHow illiterates use their mobile phones," presented at the NUI workshop, 2012.

[13] Naqvi, Muhammad Raza, et al. "Importance of Big Data in Precision and Personalized Medicine," 2020 International Congress on Human-Computer Interaction, Optimization and Robotic Applications (HORA), IEEE, 2020.

$[14] \mathrm{H}$. Shah and A. Sengupta, "Designing mobile based computational support for low-literate community health workers," International Journal of Human-Computer Studies, vol. 115, pp. 1-8, 2018.

[15]H. K. Hallingby, "Key success factors for a growing technology innovation system based on SMS Application-to-Person in Norway," Technology Analysis \& Strategic Management, vol. 28, no. 10, pp. 1123-1137, 2016.

[16] J. C. Willcox, R. Dobson, and R. Whittaker, “Oldfashioned technology in the era of 'Bling': is there a future for text messaging in health care?," Journal of medical Internet research, vol. 21, no. 12, p. e16630, 2019.

[17] S. Cuendet, I. Medhi, K. Bali, and E. Cutrell, "VideoKheti: Making video content accessible to low-literate and novice users,", pp. 28332842,2013.

[18] J. Sherwani, S. Palijo, S. Mirza, T. Ahmed, N. Ali, and R. Rosenfeld, "Speech vs. touch-tone": Telephony interfaces for information access by low literate users, pp. 447-457,2009.

[19] Jan, Sadeeq, Imran Maqsood, Iftikhar Ahmad, Majid Ashraf, and Fazal Qudus Khan., "A Systematic Feasibility Analysis of User Interfaces for Illiterate Users: A Systematic Feasibility Analysis of User Interfaces for Illiterate Users," Proceedings of the Pakistan Academy of Sciences: A. Physical and Computational Sciences, vol. 56, no. 4, pp. 75-91, 2019.

[20] I. MedhiThies, "User interface design for lowliterate and novice users: Past, present and future," Foundations and Trends in HumanComputer Interaction, vol. 8, no. 1, pp. 1-72, 2015.

[21] S. K. Shahzad, D. Ahmed, M. R. Naqvi, M. T. Mushtaq, M. W. Iqbal, and F. Munir, "Ontology Driven Smart Health Service Integration,” 
Computer Methods and Programs in Biomedicine", vol. 207, p. 106146, Aug. 2021.

[22] M. R. Naqvi, M. Aslam, M. W. Iqbal, S. Khuram Shahzad, M. Malik and M. U. Tahir, \&quot;"Study of Block Chain and its Impact on Internet of Health Things (IoHT): Challenges and Opportunities", International Congress on Human-Computer Interaction, Optimization and Robotic Applications (HORA), Ankara, Turkey,2020,pp.1-6, 2020

[23] Sabina.KC, "Accessible Information Visualization for Low literate users": An iterative Process of User experience design, 2019.

[24] Whittemore, R., Vilar-Compte, M., BurrolaMéndez, S., Lozano-Marrufo, A., Delvy, R., Pardo-Carrillo, M., De La Cerda, S., PenaPurcell, N. and Pérez-Escamilla, R., "Development of a diabetes self-management+ mHealth program: tailoring the intervention for a pilot study in a low-income setting in Mexico," Pilot and feasibility studies, vol. 6, no. 1, pp. 110, 2020.

[25] Naqvi, Muhammad Raza, Muhammad Waseem Iqbal, Syed Khuram Shahzad, Iqra Tariq, Marium Malik, Faseeha Ehsan, Natash Ali Mian, and Nadia Tabassum,"A Concurrence Study on Interoperability Issues in IoT and Decision Making Based Model on Data and Services being used during Inter-Operability," LGURJCSIT, vol. 4, no. 4, pp.73-85, 2020.

[26] Tahir, M.U., Naqvi, M.R., Shahzad, S.K. and Iqbal, M.W., "Resolving Data De-Duplication issues on Cloud," In 2020 International Conference on Engineering and Emerging Technologies (ICEET), pp. 1-5, IEEE, 2020. 